\title{
The Lethal Frequencies of Thunderstorm Sounds and Energies: A Mini Review
}

\author{
Saganuwan Alhaji Saganuwan* \\ Department of Veterinary Physiology, Pharmacology and Biochemistry, University of Agriculture, Nigeria
}

Submission: September 25, 2018; Published: October 22, 2018

*Corresponding author: Saganuwan Alhaji Saganuwan, Department of Veterinary Physiology, Pharmacology and Biochemistry, College of Veterinary Medicine, University of Agriculture, P.M.B. 2373, Makurdi, Benue State, Nigeria, Tel: $+2348027444269,+2347039309400$,

Email: pharn_saga2006@yahoo.com

\begin{abstract}
Attention of people is focused on the rain rather than the damage that can be caused by lightning. However, median lethal dose of electric current has been reported to be very low. In view of this, literatures were assessed for determination of the frequency of sound, power and energy that originated from lethal thunderstorm. Frequency of about $<4-260 \mathrm{~Hz}$ and above, and energy of $5 \times 103-10^{10} \mathrm{~J}$ from 1 stroke can kill human being, animal or damage objects severely. But generally, the range of frequency, power, current, voltage and energy from thunderstorm and lightning that can kill vary according to location, time and distance.
\end{abstract}

Keywords: Biomaterials; Metals; Titanium; Stainless steel; $\mathrm{CoCr}$ alloys

\section{Introduction}

Lightning in animals may cause burns, scratched hairs on the legs, shoulders, heart fibrillation and death that may implicate vets [1]. Thunder storms could be 15 miles in diameter and lasts for 30 minutes [2]. Lightning detection and location are very important for protection against hazard. The vast amount of energy from bombarded energetic solar and galactic cosmic ray particles creates ions that conduct below $50 \mathrm{~km}$ with effect up to $3 \mathrm{~km}$ above earth is very important [3]. Thunder lightning discharge requires determination of peak power energy for efficient conversion of electrical energy to acoustic energy [4]. Acoustic imaging helps in identification and quantification of thunder sources as a function of lightning current [5]. Thunder is a consequence of shock wave that originates from rapid expansion of air by hot lightning channel. Its perception depends on distance [6]. The wide disparities on energy dissipations in relation to acoustic energy [7] may be responsible for the inability to determine the lethal frequency of thunderstorm lightning electric current. The exact cause of lightning remains uncertain, but the charges are due to precipitation and air current [8].

\section{The Frequency and Energy of Lethal Thunder Stroke}

The total acoustic energy that originated from thunder spectrum was calculated using $\mathrm{E}$ (total acoustic energy) $=\mathrm{P}(\mathrm{t}) \pi \mathrm{R}^{2}(\mathrm{t})$ $\mathrm{dt}$. Where $\mathrm{P}$ is the total power flow and $\mathrm{R}$ is the acoustic distance of the flash, c ( $t-\mathrm{t}_{0}$ ) [9]. Energy spectrum (Q) generated by thunder is $0.5-2$ with frequencies range from $<4$ to $125 \mathrm{~Hz}$. At the low frequency of $<10 \mathrm{~Hz}$ wind noise could mask the thunder sign. The peak power flux ranges from 0.4 to $0.003 \mathrm{erg} \mathrm{cm}^{-2} \mathrm{Sec}^{-1} \mathrm{~Hz}^{-1}$ where as the average total power flux ranges from 0.17 to $19.3 \mathrm{ergs}^{-2}$ $\mathrm{sec}^{-1}$. The range of average rms pressure value is 2.2 to 24 dynes $\mathrm{cm}^{-2}$. Intra-cloud thunder spectrums with power $(28 \mathrm{~Hz})$ showed acoustic energy of $1.9 \times 10^{18}$ ergs and cloud-to-ground spectrum at $50 \mathrm{~Hz}$ exhibited acoustic energy of $6.3 \times 1018$ [4]. Several return strokes that varied in amplitude and rise time is greater than $1 \mathrm{KA}$ with frequency higher than $1 \mathrm{kHz}$ [5]. The best correlation coefficient between $\mathrm{dI} / \mathrm{dt}(\mathrm{KA} / \mu \mathrm{s})$ and $1 \mathrm{KA}$ is $2.61^{1.34}$ to $2.01^{1.28}$. The ground resistance of earthing system is $0.15-9 \Omega$. But the energy per unit of lightning is $E=1 / \pi_{o}{ }^{2} x P^{1 / 2} d t$ Whereas Ro is the initial channel of radius, $\mathrm{P}$ is the plasma resistivity and $\mathrm{t}$ dispatch [10] Energy can be reduced to $\mathrm{E}=\mathrm{Po} \pi \mathrm{R} 2$ if a few centimeters initial radius is neglected with regard to relaxation radius (several meters) [11].

The maximum frequency according to Dawson et al. [12] $\mathrm{f}_{\max }=0.63 \sqrt{\frac{P_{0}}{E}}$ The energy volume $\left(\mathrm{E}_{\text {vol }}\right)=0.015 \mathrm{P}_{\max }$ whereas $\mathrm{P}_{\max }$ is expressed in Pascal with unit $\left(\mathrm{mJ} / \mathrm{m}^{3}\right.$ or $\left.\mathrm{J} / \mathrm{m}^{3}\right) . \mathrm{E}_{\mathrm{vol}}=$ 1.23-1.26 $\mathrm{I}_{\max }^{1.64}$ [11], a voltage of $10^{9} \mathrm{~V}$ at height of $2 \mathrm{~km}$ produced $10^{10}$ joules per flash [13]. But $1 \times 10^{7} \mathrm{~J}$ per stroke and $5 \times 10^{3} \mathrm{~J} / \mathrm{m}^{3}$ at height of $2 \mathrm{~km}$ from ground level had been reported [14]. Also $\mathrm{f}_{\mathrm{m}}=(0.63)\left(C_{0} \frac{P_{0}}{E}\right)^{1 / 2}$ whereas Po and Co are the ambient pressure and sound respectively. Whereas the relaxation radii is $\left(R_{0}\right)=$ $\left(3 \mathrm{E} / 4 \pi \mathrm{P}_{0}\right)^{1 / 3}$ or $\mathrm{R}_{0}=(\mathrm{E} / \pi \mathrm{Po})^{1 / 2}[9]$. Thunder has non-stationary data [15] as they are not amenable to many standard power spectra techniques and therefore special [9]. Thunder spectra of $10 \mathrm{~Hz}$ to $150 \mathrm{~Hz}$ [16] and frequency of 180 to $260 \mathrm{~Hz}$ had been reported 
[17]. But coordinate $X=r / R_{0}$ where $r$ (spherical) and Ro (cylindrical) [17] with Brode's [18] non dimensional coordinate $(\lambda)$ differs from $X$ by the constant $(4 \pi / 3)^{1 / 3}$ with a length $(d)=2.6 R_{0}$

$$
\mathrm{f}_{\text {min }}=\frac{c}{d}=\frac{c}{2.6 R_{0}}
$$

where $\mathrm{c}$ is the speed of sound.

Also $\mathrm{d}=2.6 \frac{E}{\pi P_{0}}{ }^{1 / 2}$ with bottom $\mathrm{f}_{\text {min }}(57 \mathrm{~Hz})$ and top $\mathrm{f}_{\min }(39 \mathrm{~Hz})$.

\section{Conclusion}

The incidence of lightning varies in various parts of the world [19]. The primary frequency is about $20 \mathrm{MHz}$ [20]. Lightning prefers to strike tall trees several times [8]. Strokes could be triggered by $9.8 \mathrm{KA}$ to $297.7 \mathrm{KA} / \mu$ s [11]. The return strokes extended to $2 \mathrm{~km}$ from the cloud base to ground at $10^{10} \mathrm{~J}$ [13]. Early men considered lightning as weapon of their Gods despite people pay more attention to the rain rather than the danger of lightning [21-23].

\section{References}

1. Brightwell AH (1968) Lightning stroke in livestock. Can Velt J 9(8): 186-188.

2. National Weather Service (2016) Hazard Mitigation plan update: Protecting the Region Against All Hazards 1-6.

3. Poelman DR (2010) On the Science of Lightening: and Overview. Roya Meterological Institute of Belgium 50: 1-56.

4. Holmes CR, Brook M, Krehbel P, McCrory R (1971) On the power spectrum and mechanism of thunder. J Geophys Res 76(9): 2106-2115.

5. Deyah MA, Evans SA, Fuselia SA, Trevino J, Ramaekers J, et al. (2015) First images of thunder: acoustic imaging of triggered lightning. Geophys Res Lett 42(14): 6051-6057.

6. Rakov VA, Uman MA Lightning (2007) Physics and Effects, Cambridge University Press, Cambridge, UK.

7. Hill RD (1979) A Survey of lightning energy estimates. Rev Geophys
Space Phys 17(1): 155-164.

8. DeRosa EW (1983) Lightning and trees. J Aboricult 9(2): 51-53.

9. Few AA (1969) Power spectrum of thunder. J Geophys Res 74(28): 6926-6934.

10. Few AA (1982) Acoustic Radiations from lightning. CRC Handbook of Atmosphere 2: 257-290.

11. Depasse P (1994) Lightnin acoustic signature. J Geophys Res 99(12): 933-940.

12. Dawson GA, Richards CN, Krider EP, Uman MA (1968) Acoustic output of a long spark. J Geophys Res 73(2): 815-816.

13. Wilson CTR (1920) Investigation on Lightning discharges and on re-electric field of thunderstorms. Phys Trans Soc 1920; 221: 73-115.

14. Tiller JA, Uman MA, Lin YT, Brantley RD (1976) Electric field statistics for close lightning return strikes near Gainesvile Florida. J Geophys Res 81: 4430-4434

15. Few AA (1968) Thunder. PhD Thesis, Rice Univertisity, Houston, Texas, USA. pp. 329.

16. Bhatendu (1969) Audio frequency variations from lightning discharges. Journal of Atmospheric and Terrestrial Physics 31: 743-747.

17. Few AA, Dessler AJ (1967) A dominant 200-hertz peak in the acoustic spectrum of thunder. J Geophys Res 72 (24): 6149-6154.

18. Brode HL (1950) The blast wave in air resulting from a high temperature, high pressure sphere of air. Rand Corp Rept. pp. 72.

19. Kuleshov Y, Mackerras D, Darveniza M (2006) Spatial distribution and frequency of lightning activity and lightning flash density maps for Australia. J Geophys Res 111(19): 1-14

20. Uman MA, Rakov VA, Schmetzer GH, Rambo KJ, Crawford DE, et al. (2000) Time derivative of the electric field 10,14 and $30 \mathrm{~m}$ from triggered lightning strokes. J Geophys Res 105(12): 15577-15595.

21.http://lightningsafety.com/nlsi_info/thunder2.html

22. Lucia R, Rassavl HK, Kotovsky DA, Jordan DM, Uman MA (2015) First images of thunder: acoustic imaging of triggered lightning. Geophy Res lett 42(14): 6051-6057.
This work is licensed under Creative

Commons Attribution 4.0 License

DOI: 10.19080/CTBEB.2018.17.555954 